\title{
Did iron-sulfur containing minerals and proteins coevolve?
}

\section{KENNETH MCGUINNESS}

Rutgers University - Robertwood Johnson Medical School

Presenting Author: kenneth.mcguinness@gmail.com

Common to both the living (biosphere) and the non-living (geosphere) entities, metals stabilize protein and mineral structure and potentiate internal and external chemical reactions, respectively. Metal coordination environment distinguishes mineral type and protein reaction potential. Assuming metal coordination is highly conserved to retain protein function, similar metal coordination in minerals may suggest a common chemical evolution. This begs the question, did the same chemical forces drive the evolution of iron sulfur compounds in biochemistry and in the planetary environment or has life decoupled biochemistry from geochemical forces? If similar chemical forces drove metal coordination within proteins and minerals it is expected that metal-ligand interactions would be similar both on the atomic and cluster level. Atomic coordination site analysis shows higher Fe-S bond-length variance within minerals and higher S-Fe-S angle variance within proteins where functional differences and lattice packing may have predominantly separated $\mathrm{Fe}-\mathrm{S}$ species evolution. Cluster level analysis reveals metal-ligand coordination number distinguishes mineral and protein Fe-S clusters commonly compared as being analogous. Similarity of mineral and protein Fe coordination sites will be discussed with respect to geological time and the evolution of redox proteins. 